\title{
Sports Management of Indonesian Sports Athletics Preparations in Asian Games 2018
}

\author{
Ria Lumintuarso ${ }^{1, *}$, Suharjana ${ }^{1}$, Widiyanto ${ }^{1}$, Japhet Ndayisenga ${ }^{2}$ \\ ${ }^{1}$ Faculty of Sport Sciences, Yogyakarta State University, Yogyakarta, Indonesia \\ ${ }^{2}$ Institute of Physical Education and Sports, University of Burundi, Boulevard Mwezi Gisabo, Bujumbura, Burundi
}

Received September 20, 2020; Revised January 12, 2021; Accepted January 20, 2021

\begin{abstract}
Cite This Paper in the following Citation Styles
(a): [1] Ria Lumintuarso, Suharjana, Widiyanto, Japhet Ndayisenga, "Sports Management of Indonesian Sports Athletics Preparations in Asian Games 2018," International Journal of Human Movement and Sports Sciences, Vol. 9, No. 1, pp. 56-61, 2021. DOI: 10.13189/saj.2021.090108.
\end{abstract}

(b): Ria Lumintuarso, Suharjana, Widiyanto, Japhet Ndayisenga (2021). Sports Management of Indonesian Sports Athletics Preparations in Asian Games 2018. International Journal of Human Movement and Sports Sciences, 9(1), 56-61. DOI: $10.13189 /$ saj.2021.090108.

Copyright $(2021$ by authors, all rights reserved. Authors agree that this article remains permanently open access under the terms of the Creative Commons Attribution License 4.0 International License

\begin{abstract}
Background: Sport management plays an important role in the athletes' achievement and championship. Sports Management helps us to learn how to overview the business side of sports organization with the use of the latest trends and technologies. Sport management is applied in various fields. The benefit of sport management is to increase the quality of business whether in sport industry, physical education, but it is also used in coaching athletes during the pre-competition, the competition process, and post competition. Purpose: The purpose of this research was to evaluate the principals of sport management like: (1) planning, (2) organizing, (3) staffing, (4) leading and (5) controlling in Asian Games 2018. Design/methodology/approach: This was a qualitative descriptive study. The research sample was made of all Indonesia sports professionals in 2018' games. To collect data, the researcher conducted an assessment of service quality from planning, organizing, staff, leading and control during the Asian championship using questionnaire, interview, and observation. The Results showed that the achievement of the Indonesian athletic team was more programmed and planned, which is evident from the early age athletes were selected and coached by senior athletes. Indonesia's role in the development process was more apparent in the government support, the support of stakeholders, and academics from universities. Conclusion: Sport management is a strong tool that helps physical education teachers, sport medicine managers, and coaching training managers to decide how to improve the peak of performance and to maintain a good quality of
\end{abstract}

athletes and non-athletes.

Keywords Management, Preparation, Athletic, 2018 Asian Games

\section{Introduction}

Coaching is one of the important activities to improve performance in various sports [1]. Coaching is an attempt to provide direction and guidance in order to achieve a particular purpose. Sport coaching has therefore to be consciously planned, directed, and organized [2]. In order to provide knowledge and directions which allow to 1achieving high performance. Sports experts around the world agree on the need of stages of development to produce high sports achievements [3].

One of the factors leading to sports achievement is the rigorous development of the sport itself. To achieve maximum performance in sports, there must be regular competitions both national and international [4]. Sports achievements at national and international level are no longer a private property, but already are seen as a dignity and honor of nations. To this end, a wide range of attempts were made by local clubs, teams at the provincial, and national levels to send the athletes, both at the regional, national, or event Asean Games, and the Olympic Games.

For sport achievement, to be responsable is required in 
order to achieve an effective sports coaching through sports organizations. Of the many sports that exist in Indonesia, athletics is one sport that is nurtured and developed [5].

A study done in Greek about management has been assessed from the perceptions Greek professional football on service quality, satisfaction, repurchase intention and word-of-mouth. The sample of this study were 925 subjects. The results revealed that service quality and satisfaction predict together a significant proportion of spectators repurchase intention (the total percentage of prediction was $51 \%, \quad \mathrm{R} 2=.511, \quad \mathrm{p}<0.001)$ and word-of-mouth communication (the total percentage of prediction was $53.8 \% \mathrm{R} 2=.538, \mathrm{p}<0.001$ ) [6]. The last result showed that the more a sport event is well managed, the more proceed benefits. The functions of organizations in building and developing the national sporting activities from the scope of the clubs the bottom layer to the executive board level as the top layer is a " sine qua none condition" or an absolute necessity of its existence. Now than ever, sport organizations as a structure don't need to be handled amateurs, but must be managed by professional [7].

Taken from a variety of management investigated theory like: Planning, Organizing, Coordinating, Motivating, Controlling, Directing, Staffing, Innovation, Representation, Supervising, Communicating, Actuating, appraising, Commanding, Reporting, Executing, and Budgeting, functions like inserting, coordinating, communicating, and motivating are essential parts sports organizations [8]. One study has shown the importance of parents and siblings in achieving expert performance operating within three kinds of constraints, namely motivational, effort, and resource [9].

The success of an organization of sports is always associated with how far the achievement sportsman produced by the organization are [10]. A study done in Florida State University about sport management evaluated the relationships between service quality, core product quality, game and service satisfaction, and behavioural intentions is proposed and tested. Data were collected from spectators at a professional baseball game in Japan $(\mathrm{n}=283)$ and at two college football games in the United States $(n=343)$. The results in both Japan and the United States indicate that game atmosphere was a strong predictor of game satisfaction whereas stadium employees and facility access were the major antecedents of service satisfaction. Game satisfaction had a significant impact on behavioural intentions across the two settings[11].

Theoretically, it can be assumed that the achievements of sports organizations that can perform management functions well can be expected to produce a good performance. The main achievement benchmarks Sports in Indonesia in 2018 was the athletic achievement in the arena of Multi Event 2018 Asian Games that was hosted in Indonesia.

Athletics can be defined as a sport event that consists of a number of running, jumping, and throwing competitions. The running competition includes sprinting, middle distance running, long distance running, and marathon [12]. The jumping competition includes triple jump, high jump, pole vault, and long jump. Nevertheless, the throwing competition includes shot put, javelin, hammer, and ejection. The events are unusual raced in various championships at local, provincial, national or international levels [13].

Athletics is a sport compulsory in the championship multievent in Asia. The competition was organized with the aim to find and parenting talents of athletes especially athletic flair. The preparations for the championship were held through management, namely sports management. Sports management is a combination of management and sports. Management is the process of planning, organization, bringing leadership and control of efforts and of organization's members to use all other resources to achieve the stated goals of the organization [14].

Management plays an important role in the achievement of athletes in the championship. Not only at the committee level, but also in the management of activities undertaken by participants, namely management of the during the pre-competition, the competition process, and post competition. It can be concluded that management is very important for the achievement of a common goal, namely the achievement of athletes at the championship [15]. The field of sports management equips professionals with the skills and knowledge necessary to support sport marketing agencies, intercollegiate athletic departments, professional sports organizations, sports equipment manufacturers, and many more operations throughout the vast sports industry [16]. Sports management is a fast-paced field. One of them is dealing with teams of athletes, there are always issues that will need attention. One has not able to focus on what they are doing in the moment, but also be able to pivot quickly to something else. One will need to juggle lots of responsibilities and be able to move from task to task with flexibility [17].

Sport has become a big business with many stakeholders involved including fans, players, clubs, leagues, governing bodies, players' associations and agents, gamblers, rights owners, sports equipment manufacturers, broadcasters, sponsors of players, clubs, leagues, events, etc. In the last twenty years, most major sports have reached the professional stage in their development and have been going through a fierce commercialization process since external sponsors and broadcasters have been investing large sums of money in them.

Given the importance of sport management in championships and the lack of studies addressing how preparations of athletic branch were managed in the Asian 
Games, this research was intended at closing this gap by investigating the management of preparations of the athletic sport in the Asian Games 2018 in Indonesia. Indonesia is a large country with various games, there is a strong need of assessment about the current situation of the games in order to predict the future athletes' performance. This study will help Indonesian coach and physical trainers to know the strong and wick points in their game preparation. The outcome from this research will help others owner business to make strong their enterprise.

\section{Materials and Methods}

This study was a qualitative descriptive study. The research sample was made of all Indonesia sports professionals in 2018 games. To collect data the researcher conducted an assessment of service quality from planning, organizing, staff, leading and control during the Asian championship using questionnaire, interview, and observation. A descriptive research method is designed to collect information and find a picture of the actual situations using interviews. This descriptive study with aims to identify and find as much as possible information as well as to provide an overview of the management of the preparations of the athletic teams from Indonesia in the 2018 Asian Games in Jakarta and Palembang. In general, descriptive study was not to test specific hypotheses, but only describe how the management was held. Data collection with depth interviews were used with the head of the field coaching of the Indonesian Athletic Teams.

\section{Procedure}

The researcher submitted a questionnaire to the coaches, athletes, and staff to gathering information. A deeply interviews were addressed to the same subjects after complete the questionnaire in order to know more about the preparation of games. Not only the questionnaire and interview conducted but also a deep observational about preparation games by the researcher. After gathering information from the survey, the researcher classified them in three categories: 1) Performance Management System; (2) Performance Development Process; (3) Competition Performance Analysis. The researcher wants to find out if the preparation done predict or expect the future good performance.

\section{Result}

The results were presented in the following three factors: (1) Performance Management System; (2) Performance Development Process; (3) Competition Performance Analysis.

\subsection{Performance Management System}

Performance Management System was carried out in nine items like: (1) The right system: this system aims to prepare the various layers to ensure the achievement of sustainable and long-term. This system has been elaborated in all various areas of Indonesia, (2) Clear goals and priorities: The aim is to set up a multi-international events such as the Asian Games and Olympic Games, The current priority is to improve performance in the SEA Games and Asian Games to increase the medals gained. This objective is quite clear and measured as an index of the medals as it is a measurable outcome. Another goal is to improve achievement, (3) Measurable and realistic targets: the aims were to improve performance in the SEA Games. There was a lack of medals from 2014 where Indonesia got one gold medal, one silver, and one Bronze, raison why the goals had to be enhanced, (4) Managing organizational culture of achievement: coaching achievements such as: Development Commission, medical Commission, Coach Commission, and Commission nurseries. Field coordination meeting in a clear time frame (5) Right skills: Every field and the commission must be held by personnel who has expertise in accordance with their duties. Medical commission for example was occupied by the sports doctors, physiotherapist, and masseurs. In the Asian Games, each commission works with more intense in dealing with athletes. (6) Internal aspects and stakeholder: All rank of officials involved simultaneously with the Group WhatsApp (Social Media) management, so that each party can carry out its work with the direct control of the management in this regard held by the General Secretary. External aspects such as sponsorship and support from the government through the Ministry of Youth and Sports are to support the dominant factor, especially in terms of funding and infrastructure utilization system exercise (7) Innovation: The preparation for the Asian Games in particular by conducting engineering practice in a variety of situations, conditions such as exercise at high altitude for long-distance runners, and practice abroad for athletes such as sprinting and jumping. The use of technology has always promoted sports for detecting and evaluating the training process results, such as the application of physiology and biomechanics in general to provide more modern training methods. (8) Financial Support: the supporting from the public was to host the Asian Games, and to give optimal support. Besides, it was also a sponsor in conducting its support mainly in apparel and outfit used for training and competition, (9) SDM: that has the best human resources with good administrative system.

\subsection{Performance Development}

The performance development was based on the identification of the determinants of achievement in the 
training process. The coaches who were recruited in Asian Games had international certificates. Every coach had a powerful ability to identify the determining factors of achievement of a high performance in athletics. The coach also did not hesitate to carry out discussions and consultations with mentors who were considered to have a broader insight in coaching. The research showed that there were three types of performance development: (1) The development process of physical, technical, tactical, and mental aspects. In periodization trainings arranged by the trainer and weekly exercise (micro cycles), it seems that the coach incorporated elements of engineering, physical, and mental training process. Programming is done in general by taking into account the data and the ability of individual athletes and numbers that followed in a following match. (2) Process intensification and control exercise program: To revitalize the core exercises in the training process, athlete's dormitory concentration to monitor the activity of athletes in training. The presence of athletes and coaches' practice was not a problem in the activation of the exercise. But control training was still a problem because the system control program was implemented in general. Individual exercise program was still not done optimally because of a shortage of supervisors and mentors. (3) Test and evaluation process of the implementation of the exercise: the development of test and evaluation of each meso cycle in accordance with the needs of the exercise component. Meso cycles are arranged six-weekly which has a dominant component such as endurance exercises common in the general preparation phase and maximum strength at the end of the common preparation and power in a special preparation. The test and evaluation were also performed by following a championship or try out both domestically and abroad. The results of tests and competitions were evaluated by a meeting between the coaches national trainings to discuss the follow-up exercise. The meetings could conclude the athletes' readiness to face the next phase or the eligibility of athletes to follow the Asian Games. But on the other hand, since Indonesia was the host, the selection of a certain number of athletes was easier and some were selected despite not having the capacity required by the standard Asian Games.

\subsection{Competition Performance Analysis}

Athletics is a multi-sport event where there are determining conditions such the muscles involved, the system of energy used, and the varying movement (running, jumping, glue). Test results indicated that the general parameters of athletes Indonesia has increased quite significantly, although some athletes were not able to demonstrate competitive standards at the level of Asia. Viewed from these conditions, it is possible that Indonesian athletes are still not able to compete at the Asian level in a such big number. Factors that were still weak in supporting the achievements were: (1) physical support (endurance, core stabilization, general strength), (2) techniques also remained a constraint to Indonesian athletes in competing with Asian level athletes, (3) the equipment used, some athletes were acquainted but others were still experiencing problems and the quality of the tools used varied. The organizers had provided standard equipment so that there is no reason for athletes to feel inferior.

\section{Discussion}

The findings of this study have shown that the preparations of the Indonesia Athletic teams had a good management. On the management performance system, almost the whole management conducted by the Indonesian athletic teams showed a good performance. Many studies have showed that management is the key of success or to achieve high performance [18]. Organizational culture, internal conditions, stakeholders, innovations made, financial and human resources management are likely to provide excellence in Indonesia. However, in the guidance system, setting goals, and prioritiesand targeting, countries like Thailand are slightly ahead of Indonesia. Thailand has programs and plans talented athletes from early childhood through senior coaching athletes. Sport management involves any combination of skills related to planning, organizing, directing, controlling, budgeting, leading, and evaluating within the context of an organization or department whose primary product or service is related to sport or physical activity [19].

The process of developing the achievements also shows some of the patterns in the identification, development process of physical, technical, tactical and mental, as well as the activation and control of the exercise program. Many countries also make the process of testing and evaluating the training process. Various analyses were also conducted to develop the training process. However, there are advantages and benefits of Thailand in the engagement and support from the government as well as stakeholders and academics from universities. In many ways, in Thailand, the role of government, stakeholders, and the involvement of academics and practitioners are quite large when compared to Indonesia. Management in sport organizations provides sports development with general planning activities in the field of sports, organizes all relevant resources, processes and functions, a policy of human resources development, organized sports and business functions, and provide communication and coordination [20].

In terms of analytical performance of the competition, the teams of Indonesia has various advantages over Thailand teams. Indonesia in the 2018 Asian Games as host provided enough access for Indonesian teams to 
identify venues used in the Asian Games in 2018 which improving critical thinking and abstract reasoning skills in analyzing sport management issues and in managerial planning and decision making, demonstrating information literacy and communication skills, conceiving, planning, executing, and evaluating a sports event [21]. However, in general, in the analysis of the performance of the competition, Thailand always analyzed the condition of the athletes' performance by visually displaying the data on athletes' performance and by displaying data of the achievement attained. This implies that Thailand has the advantage in this aspect of the performance analysis of the competition.

Governance and management of the preparations of Indonesian athletic teams heading 2018 Asian Games was basically done. The management and particularly in sports management is fundamental in achieving sporting success. Basically, the management has to be consciously planned and executed.

\section{Conclusions}

Although the management was well done, the performance achieved by the Indonesian athletes was still not optimal. It was also influenced by factors outside of management that cannot be controlled. Having mentioned that, the motivation factors are also important in the achievement a good sport performance. Various motivational factors like mental factors need to be well strengthened besides the technical as well as physical factors. In the end, the management of the preparations of the Indonesian teams towards the 2018 Asian Games, Indonesia showed a good performance though not optimal. Management was divided into three aspects, namely performance management system, development process performance, and competition performance analysis. In the management of the preparation, the results were quite good although they were not maximized in the 2018 Asian Games event.

\section{Acknowledgments}

We want to express warm thank to the participants in this research who gave a written consent, and also our deep feelings of gratitude are addressed to the physical education teachers, coaches, and athletes from Indonesia for all information provided.

\section{REFERENCES}

[1] H. P. N. Perera, "Does the coach leadership behavior mediates the influence of factors affecting coach leadership behavioral styles on team success," Int. J. Hum. Mov. Sport. Sci., vol. 7, no. 3, pp. 51-57, 2019, doi: 10.13189/saj.2019.070302.

[2] S. Samur, "Organization Design in Football Management Process," Int. J. Hum. Mov. Sport. Sci., vol. 6, no. 2, pp. 3846, 2018, doi: 10.13189/saj.2018.060203.

[3] S. Junghagen, "Football clubs as mediators in sponsor-stakeholder relations," Sport. Bus. Manag. An Int. J., vol. 8, no. 4, pp. 335-353, 2018, doi: 10.1108/SBM-02-2017-0007.

[4] H. B. Shin and B. Li, "Whose games? The costs of being 'Olympic citizens' in Beijing," Environ. Urban., vol. 25, no. 2, pp. 559-576, 2013, doi: 10.1177/0956247813501139.

[5] H. Sarmento, A. Pereira, M. T. Anguera, J. Campaniço, and J. Leitão, "The Coaching Process in Football - A qualitative perspective," J. Sport. Sci. Med, vol. 3, no. 1, pp. 9-16, 2014.

[6] Y. Thamnopoulos, A. Laios, and G. Tzetzis, "The Impact of Service Quality and Satisfaction on Customers' Future Intentions, in the Sport Spectators' Context," Sport J., vol. 15 , no. 8, pp. 1-13, 2012.

[7] R. Felix, "Service Quality and Customer Satisfaction in Selected Banks in Rwanda," J. Bus. Financ. Aff., vol. 06, no. 01, pp. 1-11, 2017, doi: 10.4172/2167-0234.1000246.

[8] J. Ndayisenga and Tomoliyus, "Effect of service quality and rates on satisfaction and loyalty of customer behavior at fitness," Int. J. Hum. Mov. Sport. Sci., vol. 7, no. 2, pp. 2532, 2019, doi: 10.13189/saj.2019.070202.

[9] J. Côté, "The influence of the family in the development of talent in sport," Sport Psychol., vol. 13, no. 4, pp. 395-417, 1999, doi: 10.1123/tsp.13.4.395.

[10] W. Ranjan, "A Review of Sport Events Impact Evaluation Methods," no. July, 2016.

[11] M. Yoshida and J. D. James, "Customer satisfaction with game and service experiences: Antecedents and consequences," J. Sport Manag., vol. 24, no. 3, pp. 338-361, 2010, doi: 10.1123/jsm.24.3.338.

[12] R. Stead and M. Nevill, "The Impact of Physical Education and Sport on Education Outcomes: a Review of Literature," Loughborough University, 2010.

[13] S. N. Li and L. Jago, "Evaluating economic impacts of major sports events - A meta analysis of the key trends," Curr. Issues Tour., vol. 16, no. 6, pp. 591-611, 2013, doi: $10.1080 / 13683500.2012 .736482$.

[14] A. E. Rowell et al., "Effects of Training and Competition Load on Neuromuscular Recovery, Testosterone, Cortisol, and Match Performance During a Season of Professional Football," vol. 9, no. June, pp. 1-11, 2018, doi: 10.3389/fphys.2018.00668.

[15] T. Slack and A. Thurston, "The social and commercial impact of sport, the role of sport management," Eur. Sport Manag. Q., vol. 14, no. 5, pp. 454-463, 2014, doi: 10.1080/16184742.2014.974311.

[16] S. Allender, G. Cowburn, and C. Foster, "Understanding participation in sport and physical activity among children and adults : a review of qualitative studies," vol. 21, no. 6, pp. 
826-835, 2020, doi: 10.1093/her/cyl063.

[17] K. Opstoel et al., "Personal and social development in physical education and sports: A review study," Eur. Phys. Educ. Rev., vol. 26, no. 4, pp. 797-813, 2020, doi: $10.1177 / 1356336 \mathrm{X} 19882054$

[18] V. Delshab and S. Sadeghi Boroujerdi, "Investigating the influence of unlearning on knowledge management in sport organizations," Kybernetes, vol. 47, no. 10, pp. 2025-2040, 2018, doi: 10.1108/K-11-2017-0449.

[19] P. Warning, K. Toohey, and D. Zakus, "The content and foundations of Olympic studies: Subject profile analysis of a decade of Olympika," Esporte e Soc., vol. 4, no. 12, pp. 1-21, 2009.

[20] H. Turki, "Les olympiades internationales des sciences entre 2013 et 2016: Défauts et situation internationale," no. September, 2016

[21] E. Hübner, "Some notes on the preparations for the olympic games of 1936 and 1940: An unknown chapter in German-Finnish cooperation," Int. J. Hist. Sport, vol. 30, no. 9, pp. 950-962, 2013, doi: 10.1080/09523367.2013.781156. 